https://doi.org/10.31470/2706-7904-2020-15-105-110

\title{
PERFORMANCE ON THE PICTURE DESCRIPTION TASKS IN PATIENTS WITH LATE DEMENTIA OF THE ALZHEIMER'S TYPE
}

\section{Виконання задач опису зображсення у хворих на пізній стадії деменції типу Альцгеймера}

\author{
Eda Can \\ Ph.D. in Linguistics, Dr. Lecturer \\ Dokuz Eylül University (Turkey) \\ eda.can@deu.edu.tr \\ https://orcid.org/0000-0002-0061-1843

\section{Gülmira Kuruoğlu} \\ Ph.D. in Linguistics, Professor \\ Dokuz Eylül University (Turkey) \\ gulmira.kuruoglu@deu.edu.tr \\ https://orcid.org/0000-0002-4172-0253
}

\begin{abstract}
Linguistic problems such as word finding difficulties, writing disorders, problems in phonetic and syntactic use are one of the most important problems seen in individuals with Alzheimer's Disease $(A D)$. Compared to late onset, early onset dementia patients experience these problems at a faster rate. However; the linguistic abilities of LAD patients are quite similar to the healthy people. In this study, the picture description performance of late onset $A D$ patients and healthy people were compared in terms of affirmative, negative and interrogative sentence structures. According to the results, there is a significant difference within groups. Late onset AD patients produced more declarative and interrogative sentences in picnic picture description test.
\end{abstract}

Key words: Declarative sentences, Interrogative Sentences, Early-onset Alzheimer's disease.

\section{Introduction}

Alzheimer's Disease (AD) is the commonest form of dementia, accounting for between one-half and two-thirds of all cases. Age, genetic factors, other diseases, lifestyle, environment, head injuries, and even level of education are a variety of factors related to the causes of $\mathrm{AD}$ (Longley \& Warner, 2002). Its course is marked by a continual loss of 
neurons and their connections with other neurons that are crucial to memory and other mental functions (Growdon, 2009). AD is divided into three stages by most experts: early, middle and late. Each stages is referenced by degrees of memory loss, activity, sleep disturbance, and other characteristics (Turkington \& Mitchell, 2010).

A rare form of $\mathrm{AD}$ occurs earlier in life than normally expcted-usually before age 65 . Early onset Alzheimer's Disease (LAD) strikes often enough to be given a name: early onset familial AD. Other than the unusually early appearance, the symptoms of LAD are similar to those of AD that appear in older patients. However, some research suggests that people with LAD decline at a faster rate (Turkington \& Mitchell, 2010).

Language deficits in $\mathrm{AD}$ were studied in many research and according to these research there are major language difficulties in several aspects of language production, such as anomia, impoverished idea density and discourse coherence and a decline in grammatical complexity. Grammatical complexity clinically manifests itself through the use of less structurally complex sentences in individuals with cognitive decline (Filiou et al., 2020). In some of research which are related to the sentence length and complex sentence structures, it is revealed that the performance of AD patients' on syntactic ability differs from the healthy people. Moreover, these differences can also been observed on the two subtypes of AD as late-onset and early-onset (Can \& Kuruoglu, 2017, 2018a, 2018b, 2019a, 2019b).

Speech and language production both require significant levels of neurological function. Therefore, information derived from analyzing speech and language production (words and sentences) serves as a useful window into the health of an individual's cognitive ability (Voletti, Liss \& Berisha, 2019). In terms of this, it was aimed to find out the use of affirmative, negative and interrogative sentence structures of LAD patients using picture description tasks and compare the results with the people with normal aging.

\section{Methods and Techniques of the Research}

Connected language involves ongoing interactions among diverse cognitive processes including semantic storage and retrieval, executive functions, and working memory, which contrasts with isolated tasks such as picture naming. Picture description tasks are useful tools for detecting differences in a wide variety of language and communicative measures (Mueller et al., 2018). Starting from this point of view, Picnic Picture Description Test (from Western Aphasia Battery, Revised: Kertesz, 2007), Cookie Theft Picture Description Test (from Boston Diagnostic Examination of Aphasia: Kaplan, Goodglass \& Weintraub, 2001) were used in order to reveal the performance of EAD patients on picture description in terms of affirmative, negative and interrogative sentence structures. The mean age of EAD patients is 59.86 and all of them were diagnosed as mild or moderate EAD. 
The performance of EAD patients on picture description was recorded first and than transcribed based on the DuBois' discourse transcription symbols (1993). In their descriptions, just grammatically acceptable affirmative, negative and interrogative sentences were analysed. This analysis was supported by Qui-square test and median test.

\section{Results}

The statistical analysis started wtih the comparison of the two groups and found out that there was no significant difference within groups. With this result, second part of analysis started and all data received from the picture descriptions were analysed within tests and within groups. According to the results related to the picture descriptions, it was revealed that, the number of negative and interrogative sentences that LAD patients produced was higher in picnic picture description test compared to cookie-theft (Affirmative: \% 31 / Negative: \% 26 / Interrogative: \% 42.7) (p<0,001).

According to the results related to the group comparison, it was found out that in picnic picture and cookie-theft picture description tests there was a statistically significant difference between LAD patients and CG in terms of declarative and interrogative sentences (Picnic picture: $\mathrm{p}<0,000 /$ Cookie-theft: $\mathrm{p}<0,006$ ). In picnic picture, LAD patients produced higher amount of interrogative sentence structures compared to the $\mathrm{CG}$. However, $\mathrm{CG}$ produced more affirmative and negative sentence structures compared to LAD patients. In cookie-theft picture description test, LAD patients produced higher amount of interrogative sentence structures compared to the CG. The number of affirmative and negative sentences produced by $\mathrm{CG}$ was higher than the production of LAD patients in cookie theft.

As a result of these comparisons, it was revealed that the picture description performance of LAD patients were different from CG in terms of affirmative, negative and interrogative sentences.

\section{Conclusions}

In this study, the picture description performance of LAD patients were investigated and after the analysis it was found out that in description tests their performance differentiated. LAD patients produced more negative and interrogative sentence structures and less affirmative sentence structures compared to the age-matched healthy people.

In literature, there are some researches aimed to analyse the syntactic abilities of $A D$ patients. Only a small portion of studies have investigated AD abilities on sentence production and morphosyntactic production abilities (as cited in Curti, 2020). In some researches, the sentence production of $\mathrm{AD}$ patients were analysed and it was revealed that 
AD patients tended to use simple sentence structures more compared to the complex sentence structures (Can \& Kuruoglu, 2017, 2018a, 2018b, 2019a, 2019b).

In literature, there are also several studies related to informative language and speech features and they reveal that these features capture problems with word retrieval, semantic processing, acoustic impairment, and errors in speech and communication (Petti, Baker \& Korhonen, 2020). However, syntactic ability is another crucial subject that gives information about the language ability of people with AD. In literature there are also some studies about complex sentence structures but affirmative, negative and interrogative sentence structures were not investigated. There are some researches about the perception of words as positive, negative or neutral (Phelps et al., 1997) and the perception of pictures (Kensinger et al., 2002). In the latter, pictures were analysed and was tried to reveal the connection between perception and working memory (Kensinger et al., 2002). AD patients have working memory problems due to the deficits in neural interconnections between the posterior and frontal brain areas. Memory problems can also be the reason of difficulties in sentence comprehension and sentence production (Altmann \& McClung, 2008). Working memory has a role in sentence processing and provides linguistic information for this process (Sung, Kyung \& Hyang, 2013). Some studies related to sentence processing indicate a left-temporal network for syntactic processing and bilateral tempro-frontal networks for semantic processing (Lukic et al., 2013). The other studies are mainly examine the syntactic ability of LAD patients related with the comprehension of different sentence structures. For example, Rainville et al. (2007) found out that LAD patients' comprehension was typically affected at more advanced stages of the disease.

Consequently, in this study the picture description performance of LAD patients were investigated. LAD patients produced more negative and interrogative sentence structures and less affirmative sentence structures compared to the healthy people with normal aging. It is believed that due to sceptical behaviours and always being in a negative mood, LAD patients' sentence production was different in picture description tests.

\section{References}

Altmann, L.J., \& McClung, J.S. (2008). Effects of semantic impairment on language use in Alzheimer's disease. In Seminars in Speech and Language, 29(1), 18-31. https://doi.org/10.1055/s-2008-1061622

Can, E., \& Kuruoglu, G. (2017). Sentence Length of Turkish Patients with Early and Late-Onset Alzheimer's Disease. Humanities and Social Sciences Review, 06(02), 69-78. 
Can, E., \& Kuruoglu, G. (2018a). A comparison of Sentence Production of Turkish Patients with Early and Late-Onset Alzheimer's Disease. International Journal of Psycho-Educational Sciences, 7(1). 68-73.

Can, E., Kuruoglu, G., \& Ozsoy, A.S. (2018b). Geç başlangıçlı Alzheimer tipi demans hastalarının dil kullanımı: Basit tümce açısından inceleme. In Neslihan Kansu Yetkiner ve Mehmet Şahin (Eds.), Dilbilim ve Çevribilim Yazıları (pp. 36-47). 2. Baskı Ankara: Anı Yayıncılık.

Can, E., \& Kuruoğlu, G. (2019a). Language Changes in Late-Onset Alzheimer's Disease. Psycholinguistics, 25(2), 50-68. https://doi.org/10.31470/2309-1797-2019-25-2-50-68

Can, E., \& Kuruoğlu, G. (2019b). Spontaneous Speech in Dementia. Psycholinguistics, 26(2), $175-$ 189. https://doi.org/10.31470/2309-1797-2019-26-2-175-189

Curti, S. (2020). The Morphosyntax Interface in Alzheimer's Disease.

Du Bois, J. W., Schuetze-Coburn, S., Cumming, S., \& Paolino, D. (1993). Outline of discourse transcription. In Jane A.Edwards \& Martin D. (Eds.), LampertTalking Data: Transcription and coding in discourse research (pp. 45-89). New York: Psychology Press.

Filiou, R.P., Bier, N., Slegers, A., Houzé, B., Belchior, P., \& Brambati, S.M. (2020). Connected speech assessment in the early detection of Alzheimer's disease and mild cognitive impairment: a scoping review. Aphasiology, 34(6), 723-755. https://doi.org/10.1080/02687038.2019.1608502

Growdon, J.H. (2009). A Guide to Alzheimer's Disease. Harvard Health Publications.

Kaplan, E., Goodglass, H., \&Weintraub, S (2001). Boston naming test (2nd ed.). Philadelphia, PA: Lippincott Williams \& Wilkins.

Kensinger, E. (1996). Early and Late Onset as Subdivisions of Alzheimer's Disease. Harvard Brain (pp. 26-36).

Kertesz, A. (2007). Western Aphasia Battery (Revised) PsychCorp. San Antonio.

Lukic, S., Bonakdarpour, B., Den Ouden, D., Price, C., \& Thompson, C. (2013). Neural Mechanisms of Verb and Sentence Production: A Lesion-deficit Study. Procedia-Social and Behavioral Sciences, 94, 34-35. https://doi.org/10.1016/j.sbspro.2013.09.014

Longley, M., \& Warner, M. (2002). Alzheimer's disease: an introduction to the issues. In Alzheimer's disease: policy and practice across Europe (pp. 11-20). CRC Press.

Mueller, K.D., Hermann, B., Mecollari, J., \& Turkstra, L.S. (2018). Connected speech and language in mild cognitive impairment and Alzheimer's disease: A review of picture description tasks. Journal of Clinical and Experimental Neuropsychology, 40(9), 917-939. https://doi.org/10.1080/13803395.2018.1446513

Rainville, C., Caza, N., Belleville, S., \& Gilbert, B. (2007). Neuropsychological assessment. Clinical Diagnosis and Management of Alzheimer's. Editor Serge Gauthier. UK: Informa.

Petti U, Baker S, \& Korhonen A. (2020). A systematic literature review of automatic Alzheimer's disease detection from speech and language. Journal of the American Medical Informatics Association, 27(11), 1784-1797. https://doi.org/10.1093/jamia/ocaa174 
Psycholinguistics in a Modern World - 2020. Proceedings of the 15th International Scientific and Practical Conference (Pereiaslav-Khmelnytskyi, 22-23 October, 2020)

Phelps, E.A., LaBar, K.S., \& Spencer, D.D. (1997). Memory for emotional words following unilateral temporal lobectomy. Brain and Cognition, 35(1), 85-109. https://doi.org/10.1006/brcg.1997.0929

Sung, J.E., Kyung, K.J., \& Hyang, J.J. (2013). Working Memory Capacity and its Relation to Passive Sentence Comprehension in Persons with Mild Cognitive Impairment. In Clinical Aphasiology Conference: Clinical Aphasiology Conference.

Turkington, C., \& Mitchell, D.R. (2010). The Encyclopedia of Alzheimer's Disease. Infobase Publishing. 